\title{
Estudantes da Educação de Jovens e Adultos: considerações sobre o perfil e desempenho escolar
}

\author{
Students of Adult Education: Considerations on the profile and academic \\ performance
}

\section{Estudiantes de la Educación de Jóvenes y Adultos: consideraciones acerca del perfil y del desempeño escolar}

\author{
Andresa Aparecida Ferreira' \\ Selma de Cássia Martinelli" \\ 'Universidade Estadual de Campinas, Campinas - Brasil. E-mail: andresaaferreira@yahoo.com.br \\ "Universidade Estadual de Campinas, Campinas - Brasil. E-mail: selmacm@unicamp.br
}

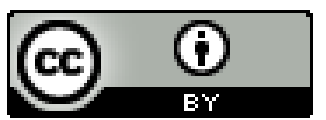

Educação: teoria e prática, Rio Claro, SP, Brasil - eISSN: 1981-8106

Está licenciada sob Licença Creative Common

\section{Resumo}

O presente estudo teve como intuito investigar o perfil e o desempenho escolar de jovens e adultos em processo de alfabetização. A escassez de dados empíricos relativos aos estudantes adultos, principalmente que retornam à escola em idade não regular, estão presentes tanto na literatura internacional quanto nacional. $\mathrm{O}$ estudo foi realizado com estudantes que participam da Educação de Jovens e Adultos - EJA, em escolas públicas da rede de ensino municipal, de uma cidade do interior do estado de São Paulo. A amostra foi composta por 67 participantes que realizaram uma atividade de avaliação de desempenho escolar e responderam a um questionário que investigava aspectos relativos ao sexo, idade e motivos de abandono e retorno aos estudos. Para fins de análise os participantes foram divididos em três grupos, em função da faixa etária: grupo 1 ( 14 a 24 anos de idade); grupo 2 (27 a 38 anos de idade) e grupo 3 (40 a 61 anos de idade). A análise foi realizada através de estatística descritiva e comparativa. Os resultados apontaram que os estudantes, em sua maioria, interromperam os estudos por motivo de trabalho e retornaram à escola em busca de realização pessoal. Quanto 
ao desempenho escolar, os estudantes apresentaram baixo desempenho em escrita e aritmética e bom desempenho em leitura.

Palavras-chave: Alfabetização. Desempenho escolar. Educação de jovens e adultos.

\begin{abstract}
This study was aimed to investigate the profile and academic performance of adults in the literacy process. The lack of empirical data on adult students, mainly those returning to not regular old program, is present in both the international and national literature. The study was conducted with students participating in the Educação de Jovens e Adultos - EJA, in public schools in a city of São Paulo state, Brazil. Sixty seven students participated responding a questionnaire and an academic assessment. The questionnaire was composed by questions related to sex, age and reasons for leaving and returning to school. For analysis purposes, participants were divided into three groups according to age: group 1 (14-24 years old); group 2 (27 to 38 old ) and group 3 (40 to 61 years old). For analysis process it was used descriptive and comparative statistics. The results showed that students, mostly discontinued studies due to work and returned to school in search of personal fulfillment. As the academic performance, students had low performance in writing and arithmetic and good performance in reading.
\end{abstract}

Keywords: Literacy. Academic performance. Education of youth and adults.

\title{
Resumen
}

El presente estudio tuvo como objetivo investigar el perfil y el desempeño escolar de jóvenes y adultos en proceso de alfabetización. La escasez de datos empíricos relativos a los estudiantes adultos, sobre todo, a los mayores que vuelven a la escuela figuran tanto en la literatura internacional como en la nacional. Dicho estudio se realizó con alumnos que participan de la Educación de Jóvenes y Adultos en instituciones públicas de la municipalidad de una ciudad del interior de la provincia de São Paulo. La muestra se compuso de 67 partícipes que realizaron una actividad de evaluación de desempeño escolar y respondieron una encuesta que averiguaba aspectos referentes al sexo, edad y motivos de abandono y retorno a los estudios. A fin de analizar datos, los participantes fueron separados entres grupos considerando su rango etario: grupo 1 (14 a 24 años); grupo 2 (27 a 38 años) y grupo 3 (40 a 61 años). El análisis se produjo a través de estadística descriptiva y comparativa. Los resultados señalaron que el alumnado, en su gran parte, interrumpió los estudios por cuestiones laborales y volvieron a la escuela en la búsqueda de realización personal. Encuanto al desarrollo escolar, los alumnos presentaron bajo desempeño en escritura y matemáticas y un buen desempeño en lectura. 
Palabras clave: Alfabetización. Desempeño escolar. Educación de jóvenes y adultos.

A Educação de Jovens e Adultos-EJA percorreu um longo caminho até se configurar na modalidade de ensino atual. Segundo Haddad e Di Pierro (2000), a educação de jovens e adultos se inicia com a colonização do Brasil, com o trabalho de catequização dos jesuítas. Gadotti (2003) fornece um panorama detalhado do que foi a história da educação de adultos no Brasil, podendo-se falar em três períodos.

No período que vai de 1946 a 1958 foram realizadas grandes campanhas nacionais de iniciativa oficial, chamadas de "cruzadas", que tinham por objetivo erradicar o analfabetismo; no segundo período (1958 a 1964), tem-se a implementação do Plano Nacional de Alfabetismo de Adultos, dirigido por Paulo Freire; e o terceiro período, iniciado na década de 80 e que perdura até os dias atuais, várias iniciativas foram implementadas. Na década de 90 , com a Lei de Diretrizes e Bases da Educação Nacional - LDB (LEI 9394/96), passa a ser assegurado à educação de jovens e adultos a gratuidade e oportunidades educacionais apropriadas, considerando as características do alunado (GADOTTI, 2003).

Sabe-se que o ensino destinado a Educação de Jovens e Adultos é historicamente escasso no Brasil e que, atualmente, se torna ainda mais importante o oferecimento dessa modalidade, uma vez que o Brasil integra os países que fazem parte do E-9, consórcio das nove nações mais populosas que aconteceu em 1993, como desdobramento da Conferência Mundial de Educação para Todos, em Jomtien, Tailândia, em 1990. O E-9 refere-se aos países onde vivem mais da metade da população do mundo, assim como quase metade das crianças fora da escola e dois terços dos analfabetos: Bangladesh, Brasil, China, Egito, Índia, Indonésia, México, Nigéria e Paquistão. O E-9 tem por finalidade construir uma agenda especial para os países onde vivem cerca de $70 \%$ dos jovens, adultos e idosos analfabetos do mundo (RELATÓRIO EDUCAÇÃO PARA TODOS NO BRASIL 2000-2015).

Em nosso país, os índices oficiais do governo indicam que houve uma diminuição no número de analfabetos pois, ao longo dos últimos anos a taxa de analfabetismo das pessoas com 15 anos ou mais vem sendo reduzida, passando de 12,4\% no ano 2001 para 8,7\% em 2012 (PNAD, 2012). Mas, ainda assim, a taxa de analfabetismo continua alta, principalmente se considerarmos as disparidades existentes entre as regiões. Todos os estados da Região Nordeste apresentaram taxas de analfabetismo mais elevadas que os 8,7\% verificados para o Brasil. Em 2012, a taxa para a Região Nordeste foi de $17,4 \%$ e para o Norte foi de $10 \%$, enquanto no Centro-Oeste assume o valor de 6,7\%, no Sudeste de 4,8\% e no Sul de 4,4\% (RELATÓRIO EDUCAÇÃO PARA TODOS NO BRASIL 2000-2015).

Se observarmos dados de uma análise mais detalhada em que se considera não só o índice de analfabetos, mas aqueles que possuem nível básico de alfabetização (analfabetos funcionais), esse percentual cresce consideravelmente. Em 2012, o Indicador de Alfabetismo Funcional - INAF/2011 - 2012 revelava que o índice de analfabetismo funcional era alto, atingindo $27 \%$, dos quais $6 \%$ podiam ser considerados analfabetos absolutos, apesar de terem 
cursado de um a quatro anos do ensino fundamental. Se somarmos a esse percentual as pessoas com nível básico de alfabetização, o número crescia para 74\%. Isso significava que apenas 26\% dos jovens e adultos conseguiam atingir o nível pleno de habilidades, o que é esperado do jovem ao completar os nove anos do ensino fundamental. Esses índices revelavam números alarmantes, demonstrando que pouco se havia avançado nos últimos anos.

Esses indicadores apontam ser um dos maiores desafios brasileiros à redução do analfabetismo, traduzido por meio da diminuição da desigualdade de acesso às oportunidades educacionais às pessoas de baixa renda. Essa perspectiva reforça a necessidade de investimento na qualificação da ação alfabetizadora e na ampliação dos mecanismos de garantia da continuidade dos estudos aos egressos de turmas de alfabetização (RELATÓRIO EDUCAÇÃO PARA TODOS NO BRASIL 2000-2015).

A complexidade dessa realidade que se apresenta e a manutenção desse quadro, na realidade nacional, tem sido abordada por muitos pesquisadores. Esses estudos têm permitido se pensar e refletir sobre essa questão a partir de diferentes enfoques. Na maioria, esses estudos abordaram questões de políticas públicas (HADDAD; DI PIERRO, 2000; CATELLI; GISI; SERRAO, 2013; VOLPE, 2013; BARCELOS, 2014; HASS; GONÇALVES, 2015; PIERRO; HADDAD, 2015). Um outro enfoque mais comumente encontrado nas pesquisas e que também é interesse do presente estudo, esteve relacionado ao perfil dos estudantes da EJA (ANJOS; GOMES; SOUZA, 2012; CALIATTO; MARTINELLI, 2005, 2008, 2013; CAMARGO; MARTINELLI, 2006; NAIFF; NAIFF, 2008; SIQUEIRA, 2009).

Naiff e Naiff (2008) objetivaram identificar possíveis representações sociais que alunos de um programa de Educação de Jovens e Adultos (EJA), de uma escola estadual localizada no município do Rio de Janeiro, possuem sobre o tema "estudar", relacionando-as com os motivos que os levaram tanto a evadir quanto a retornar à escola. Os autores evidenciaram que a necessidade de contribuir com a renda da família foi a principal justificativa para os participantes terem deixado de estudar. Por outro lado, os autores chamam a atenção de que as exigências de um mercado de trabalho moderno, que necessita cada vez mais de mão de obra qualificada e a pequena remuneração disponível para os empregos de baixa qualificação trazem novamente este sujeito ao universo escolar.

Siqueira (2009) investigou as razões pelas quais homens e mulheres adultos retornam à escola após muitos anos fora do ambiente escolar. Dentre os diversos motivos apontados, o que mais se destacou foi a busca por qualificação profissional, aquisição de conhecimentos e relações interpessoais. Também foram apontados motivos relacionados à busca de melhores condições de vida, incentivo ao estudo dos filhos, ter acesso às atualidades, recuperar o "tempo perdido", desenvolver uma melhor comunicação com as pessoas e melhorar a autoestima.

Ao tratar do perfil dos estudantes da EJA, Anjos; Gomes e Souza (2012) identificaram a presença marcante de estudantes jovens e que apontaram como o principal motivo de abandono da escola a necessidade de adentrar no mercado de trabalho. As autoras também investigaram os motivos pelos quais os estudantes retornaram à escola e constataram que o 
retorno teve fundamento na busca de conhecimentos e na necessidade de aperfeiçoamento para o mercado de trabalho.

No estudo de Caliatto e Martinelli (2013) com estudantes e ex-estudantes da EJA, também investigou-se as características desse público e sua relação com o processo escolar. As autoras constataram que os estudantes deixaram o ensino regular primeiramente pela necessidade de ajudar a família e, em segundo lugar, por motivos de ordem pessoal, tais como: desânimo, falta de interesse ou falta de consciência sobre a importância dos estudos e da escola. As autoras também investigaram a escolha da EJA pelos estudantes, no retorno aos estudos, e constatou que os motivos estavam relacionados às vantagens oferecidas pelo curso, como o aproveitamento do tempo e oferta de horários. Para os ex-estudantes, a resposta mais presente relacionou-se à necessidade imposta pelo mercado de trabalho, como conclusão de um nível de ensino para permanência do trabalhador na função ou no emprego.

Bem menos presente na literatura estão os estudos voltados à investigação de aspectos relativos à aprendizagem desses estudantes. Com uma perspectiva de investigar a percepção dos alunos, Camargo e Martinelli (2006) propuseram um estudo que buscou conhecer, entre outras questões, as reais dificuldades desses alunos com o processo de aprendizagem escolar. Identificaram que na percepção dos mesmos, suas maiores dificuldades estavam relacionadas principalmente com a leitura (20,43\%), com o escrever corretamente - pontuação, acentos, vírgulas, agrupamento e separação de sílabas e letras - $(17,20 \%)$, com as atividades matemáticas - contas, expressões numéricas, tabuadas, confusão entre os números, sinais $(12,90 \%)$. Também apontaram dificuldades de ordem pessoal, tais como: ter que estudar sozinho, ter idade avançada, nunca ter frequentado a escola, baixa visão, falta de tempo para estudar em casa, locomoção até escola, dentre outros $(9,68 \%)$.

Com um interesse mais pontual e relativo às reais aquisições escolares dos estudantes da EJA, objetivo também do presente trabalho, Caliatto e Martinelli (2005) se propuseram a analisar o emprego da grafia correta por alunos que retomaram os estudos na fase adulta. Dentre os principais resultados, as autoras encontraram erros mais frequentes como generalização de regras, colocação de sinais gráficos e/ou acentos, alterações decorrentes de confusão entre as terminações am e ão, erros decorrentes da possibilidade de representações múltiplas, em que um mesmo som pode ser grafado por várias letras ou, ao contrário, alterações ortográficas decorrentes do apoio na oralidade, erros categorizados por acréscimo ou omissões de letra e erros de letras parecidas.

Em outro estudo, Caliatto e Martinelli (2008) também investigaram a escrita ortográfica em atividade de ditado e de reescrita de uma lenda, em alunos da modalidade de EJA. Os dados apontaram para erros como apoio na oralidade, mais especificamente quando se trata de palavras que empregam sílabas compostas, dígrafos e letras que representam vários sons. Na escrita de frases e de textos, constatou-se dificuldade de segmentar as palavras. As autoras apontaram que esses tipos de erros podem dificultar a leitura e compreensão das palavras escritas e serem um indicativo de que talvez esses estudantes ainda não tenham se apropriado da escrita de maneira funcional. 
A revisão da literatura revelou que se conhece pouco a respeito dessa população de estudantes. Embora a pesquisa com este público tenha avançado um pouco e disponibilize dados empíricos relativos ao perfil do aluno da EJA, é importante ressaltar que as condições sociais se modificam constantemente, modificando também as características desse público, o que impõe a necessidade de estudos atuais e que revelem o momento atual dos estudantes que não concluíram o ensino regular na idade prevista. Por outro lado destaca-se que quase não se tem dados empíricos que permitam saber sobre os conhecimentos básicos desses alunos e relativos a escrita, leitura e aritmética. Considerando esses aspectos, o presente estudo se propôs como objetivo investigar o perfil dos alunos da educação de jovens e adultos (EJA), em processo de alfabetização, quanto ao sexo, idade, estado civil e motivo de interrupção e retorno aos estudos e avaliar aspectos da escrita, leitura e aritmética.

\section{Metodologia}

\subsection{Participantes}

Participaram do estudo 67 estudantes, matriculados regularmente no programa de Educação de Jovens e Adultos - Seguimento I (Pós-alfabetização - EJA). No município em que a pesquisa foi realizada, a EJA referente ao Ensino Fundamental, que corresponde do $1^{\circ}$ ao $9^{\circ}$ ano, é dividida em dois seguimentos. O Seguimento I corresponde aos primeiros anos do Ensino Fundamental ( $1^{\circ}$ ao $5^{\circ}$ anos) e o Seguimento II aos últimos anos do ensino Fundamental $\left(6^{\circ}\right.$ ao $9^{\circ}$ anos). O Seguimento I é subdividido em Alfabetização e Pósalfabetização. Em tese, o Seguimento I (alfabetização) é composto por alunos analfabetos absolutos, ou seja, que não têm domínio da leitura e da escrita. Já o Seguimento I (pós alfabetização) é composto por alunos que já possuem domínio da leitura e escrita ainda que em nível inicial. Dessa forma, foram escolhidos para participar da pesquisa os estudantes do Seguimento I (pós-alfabetização), já que o presente estudo previa a aplicação de instrumentos que exigiam um nível pelo menos inicial de alfabetização.

A amostra deste estudo foi composta por $50,7 \%$ de participantes do sexo feminino e 49,3\% do sexo masculino, escolhida por conveniência e realizada em cinco escolas da rede pública municipal, de uma cidade do interior do estado de São Paulo, que atendem alunos da Educação de Jovens e Adultos. Considerou-se para fins das análises a separação dos participantes por grupos de faixa etária, uma vez que integram esta modalidade de ensino estudantes com idades muito distintas. Foram constituídos três grupos: grupo 1 ( 14 a 24 anos de idade); grupo 2 ( 27 a 38 anos de idade) e grupo 3 ( 40 a 61 anos de idade).

\subsection{Instrumentos}

Questionário sobre informações pessoais. O questionário sobre informações pessoais foi elaborado pelas autoras a fim de obter dados sobre o perfil dos estudantes, bem como 
sobre os motivos que os levaram a interromper os estudos e posteriormente a retornar aos bancos escolares. No questionário, constam os itens que deveriam ser preenchidos pelos participantes quanto à idade, sexo e estado civil e é composto pelas seguintes questões: 1) Qual o motivo que levou você a parar de estudar? Seguida das alternativas: pai/mãe não autorizaram; trabalho; vontade própria; outros. 2) Por que você voltou a estudar? Seguida das alternativas: trabalho; realização pessoal; outros.

Teste de Desempenho Escolar - TDE (STEIN, 1994). O TDE é um teste elaborado para alunos do ensino regular e que cursam do $1^{\circ}$ ao $6^{\circ}$ ano. Apesar do teste não ser destinado aos alunos da EJA, considerou-se ser aplicável a esses alunos devido ao seu nível de escolarização, uma vez que o grupo aqui estudado pertence ao Seguimento I (pósalfabetização). É um instrumento que possui três subescalas: a subescala de escrita com pontuação máxima de 35 pontos; a subescala de aritmética com 38 pontos e a subescala de leitura com 70 pontos; totalizando a pontuação geral do TDE em 143 pontos. Cada item dos subtestes tem o valor de um ponto e a soma de acertos de cada subteste corresponde ao Escore Bruto. A soma dos Escores Brutos dos três subtestes vem a ser o Escore Bruto Total. Para análise dos dados será tomado como referência a pontuação bruta em cada subteste e o ponto médio em cada um dos subtestes, a saber: TDE escrita (17,5 pontos), TDE aritmética (19 pontos), TDE leitura (35 pontos) e TDE geral (71,5 pontos).

\subsection{Procedimentos}

O procedimento de coleta de dados foi realizado após aprovação do Comitê de Ética em Pesquisa - CEP da UNICAMP, Parecer n²45411 e da Secretaria de Educação do Município em que foi realizada a coleta de dados. Foi solicitada a anuência dos sujeitos mediante assinatura do Termo de Consentimento Livre e Esclarecido. A aplicação dos instrumentos foi realizada durante o horário regular das aulas, de forma coletiva, com exceção do subteste de leitura (TDE), que foi aplicado individualmente, em uma sala de aula reservada para a coleta dos dados. A coleta de dados foi realizada em vinte dias, ao longo de dois meses, visto que os alunos da EJA têm um índice baixo de frequência.

\subsection{Análise dos dados}

Foram realizadas análises descritivas referentes ao sexo, idade, estado civil e motivos de interrupção e retorno aos estudos dos estudantes. Os dados relativos à escrita, leitura e aritmética foram analisados por meio de estatística descritiva e comparativa com o uso do teste de Kruskall-Wallis. Foram considerados significantes valores de $p$ menores ou iguais a 0,05 . 


\section{Resultados}

Serão apresentados dois blocos de resultados. A primeira parte da análise se refere aos dados descritivos relativos à caracterização da amostra de participantes pertencentes à EJA e, posteriormente, dados descritivos e análise das diferenças entre os grupos relativos ao desempenho escolar.

\subsection{Caracterização dos Participantes}

Dados dos participantes agrupados por faixa etária encontram-se discriminados na Tabela1.

Tabela 1: Grupos de participantes por faixa etária.

\begin{tabular}{ccc}
\hline Idade & N & Porcentagem \\
\hline Grupo 1 (14 - 24) & 14 & $21 \%$ \\
Grupo 2 (27 - 38) & 28 & $42 \%$ \\
Grupo 3 (40 - 61) & 25 & $37 \%$ \\
Total & 67 & $100 \%$ \\
\hline
\end{tabular}

Conforme verificado na Tabela 1, o grupo com maior porcentagem de participantes é o com faixa etária entre 27 a 38 anos, que corresponde a $42 \%$ da amostra e o grupo com menor porcentagem é o de participantes mais novos, com idades entre 14 e 24 anos. Quanto à predominância do sexo dos participantes em cada grupo, pode-se dizer que no Grupo 1 há mais participantes do sexo masculino, enquanto nos grupos 2 e 3 a predominância foi do sexo feminino. Dados relativos ao estado civil e sexo dos participantes, em cada uma dessas categorias, também são descritos. A Tabela 2 mostra o estado civil dos participantes da pesquisa e a frequência em cada segmento. 
Tabela 2: Estado civil dos participantes.

\begin{tabular}{lllllllc}
\hline & \multicolumn{2}{l}{ Grupo 1 } & Grupo 2 & Grupo 3 & Geral \\
\hline Estado Civil & $\mathrm{N}$ & $\%$ & $\mathrm{~N}$ & $\%$ & $\mathrm{~N}$ & $\%$ & Porcentagem \\
Solteiro & 14 & 20,9 & 13 & 19,4 & 04 & 6,0 & $46,3 \%$ \\
Casado & 0 & 0 & 13 & 19,4 & 12 & 17,9 & $37,3 \%$ \\
Separado / divorciado & 0 & 0 & 01 & 1,5 & 06 & 8,9 & $10,4 \%$ \\
Amasiado & 0 & 0 & 0 & 0 & 0 & 0 & $0 \%$ \\
Viúvo & 0 & 0 & 01 & 1,5 & 03 & 4,5 & $6 \%$ \\
Total & 14 & 20,9 & 28 & 41,8 & 25 & 37,3 & $100 \%$ \\
\hline
\end{tabular}

A Tabela 2 mostra que a maioria dos participantes era solteiro, seguidos pelos casados. No que diz respeito ao estado civil dos participantes, pode-se dizer que no grupo 1, referente aos participantes mais jovens, houve predominância dos solteiros. Os participantes do grupo 2 dividiam-se entre solteiros e casados, enquanto no grupo 3 , composto por participantes mais velhos, a maioria era casada, seguido dos separados ou divorciados.

Tabela 3: Sexo dos participantes por estado civil.

\begin{tabular}{lllllllll}
\hline & \multicolumn{2}{l}{ Grupo 1 (\%) } & \multicolumn{2}{l}{ Grupo 2 (\%) } & \multicolumn{2}{l}{ Grupo 3 (\%) } & \multicolumn{2}{l}{ Geral (\%) } \\
\hline Estado Civil & Fem & Masc & Fem & Masc & Fem & Masc & Fem & Masc \\
Solteiro & 35,7 & 64,3 & 17,9 & 28,6 & 4 & 12 & 32,4 & 60,6 \\
Casado & 0 & 0 & 32,1 & 14,2 & 28 & 20 & 47,0 & 27,3 \\
$\begin{array}{l}\text { Separado, } \\
\text { Divorciado }\end{array}$ & 0 & 0 & 3,6 & 0 & 8 & 16 & 8,8 & 12,1 \\
Amasiado & 0 & 0 & 0 & 0 & 0 & 0 & 0 & 0 \\
Viúvo & 0 & 0 & 3,6 & 0 & 12 & 0 & 11,8 & 0 \\
\hline
\end{tabular}

Considerando o estado civil dos participantes, na Tabela 3, é importante apontar que entre os solteiros, a maioria era do sexo masculino e entre os casados predominava o sexo feminino. Já quanto aos participantes que se declararam separados ou divorciados, a maioria 
era do sexo masculino e, entre os viúvos, todos eram mulheres. Os dados também revelaram a predominância do sexo de acordo com o estado civil, dentro de cada grupo. No grupo 1, em que a predominância era dos solteiros, a maioria era homem, no grupo 2 também havia mais homens entre os solteiros e mais mulheres entre os participantes casados. $\mathrm{O}$ mesmo se verifica no grupo 3, referente aos participantes mais velhos, pois havia mais homens entre os solteiros e mais mulheres entre os participantes casados. Ainda com relação ao grupo 3, também observa-se que havia mais homens entre os participantes separados/divorciados e todos os participantes viúvos eram do sexo feminino.

Sobre os motivos pelos quais os participantes deixaram de frequentar a escola na idade própria e o porquê de retornarem aos bancos escolares, as respostas mais frequentes foram o fato dos pais não terem autorizado prosseguir os estudos; terem deixado os estudos para começar a trabalhar; terem interrompido os estudos por vontade própria; e, por último, o motivo outros. Os dados referentes a essa questão podem ser observados nas figuras de 1 a 8 , tanto com relação aos grupos de idade quanto com relação à amostra de participantes como um todo.

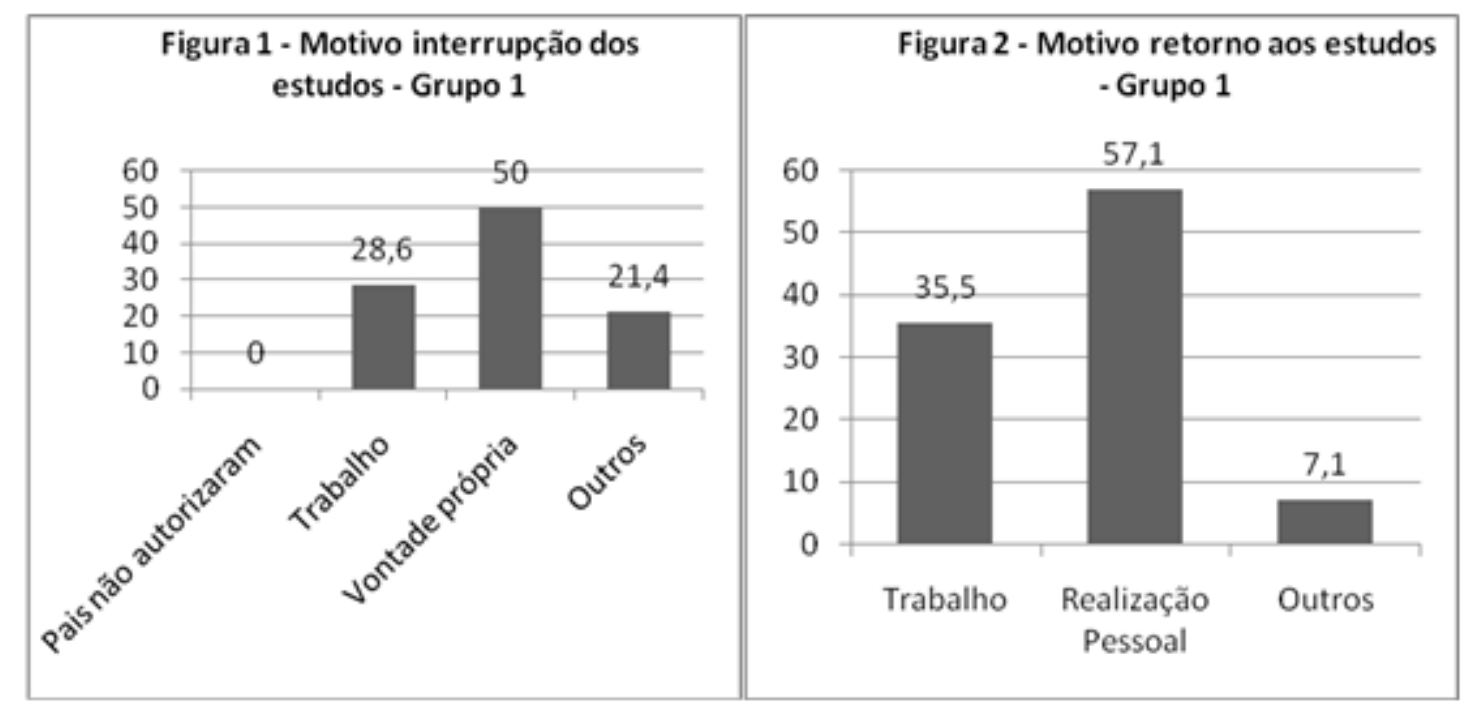

Figuras 1 e 2: Motivos de interrupção dos estudos e retorno aos estudos dos participantes do Grupo 1.

A partir da Figura 1, pode-se observar que a maioria dos participantes mais jovens interrompeu seus estudos por vontade própria e voltou a estudar por motivos de realização pessoal e como forma de inserção na sociedade letrada (ver Figura 2). As figuras 3 e 4 mostram os mesmos dados, mas referentes ao grupo 2. 


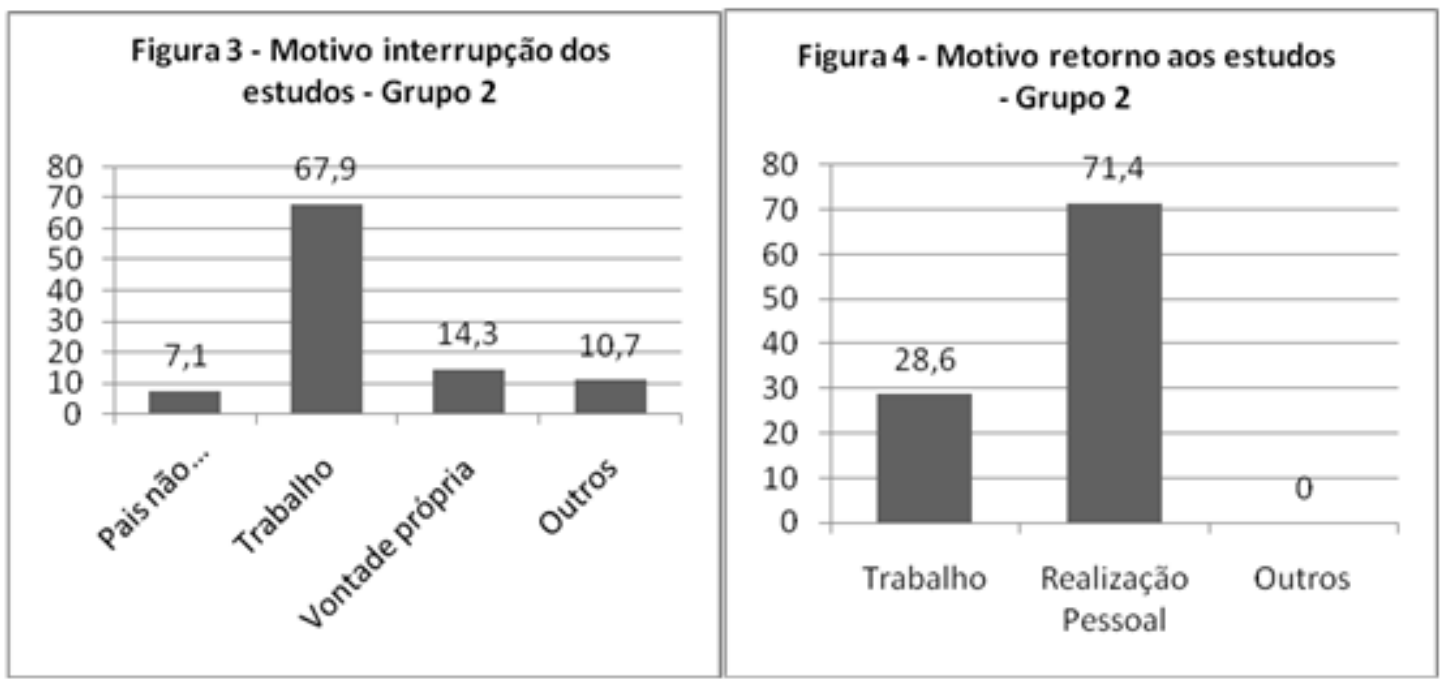

Figuras 3 e 4: Motivos de interrupção dos estudos e retorno aos estudos dos participantes do Grupo 2.

A Figura 3, referente ao motivo de interrupção dos participantes do grupo 2, mostra que a maioria dos participantes parou de estudar porque precisou se inserir no mercado de trabalho. E, quanto ao retorno aos estudos, a maioria dos participantes do grupo 2 relatou ter voltado para a escola também por realização pessoal (ver Figura 4). Os mesmos dados se revelam quanto ao grupo 3, como mostram as figuras 5 e 6 .

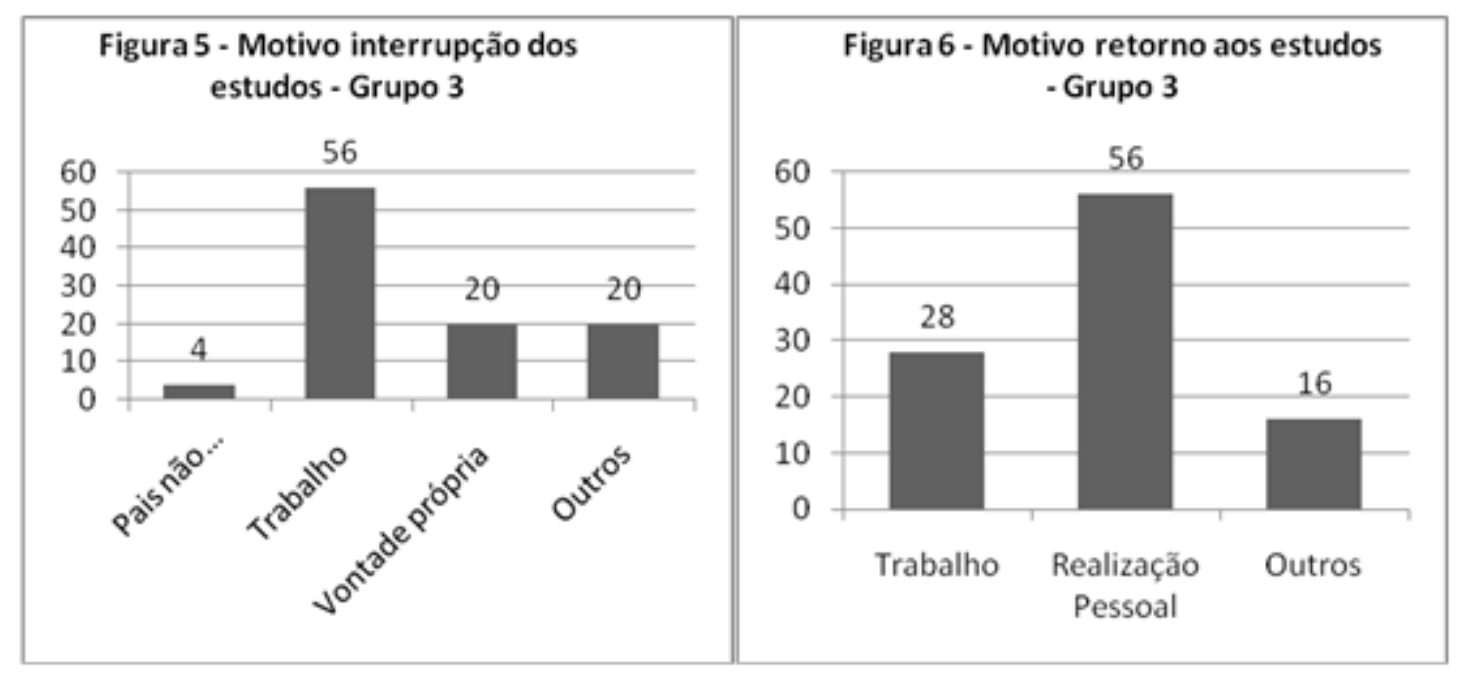

Figuras 5 e 6: Motivos de interrupção dos estudos e retorno aos estudos dos participantes do Grupo 3.

O grupo 3, formado pelos participantes mais velhos, também revela o fato de ter interrompido seus estudos por motivo de trabalho, como mostra a Figura 5. Quanto ao motivo do retorno aos bancos escolares, observa-se a partir da Figura 6, que o grupo 3 também relata que se trata de realização pessoal. A análise a seguir apresenta os resultados desses motivos 
considerando-se a amostra como um todo e independentemente da faixa etária (ver Figuras 7 e 8).

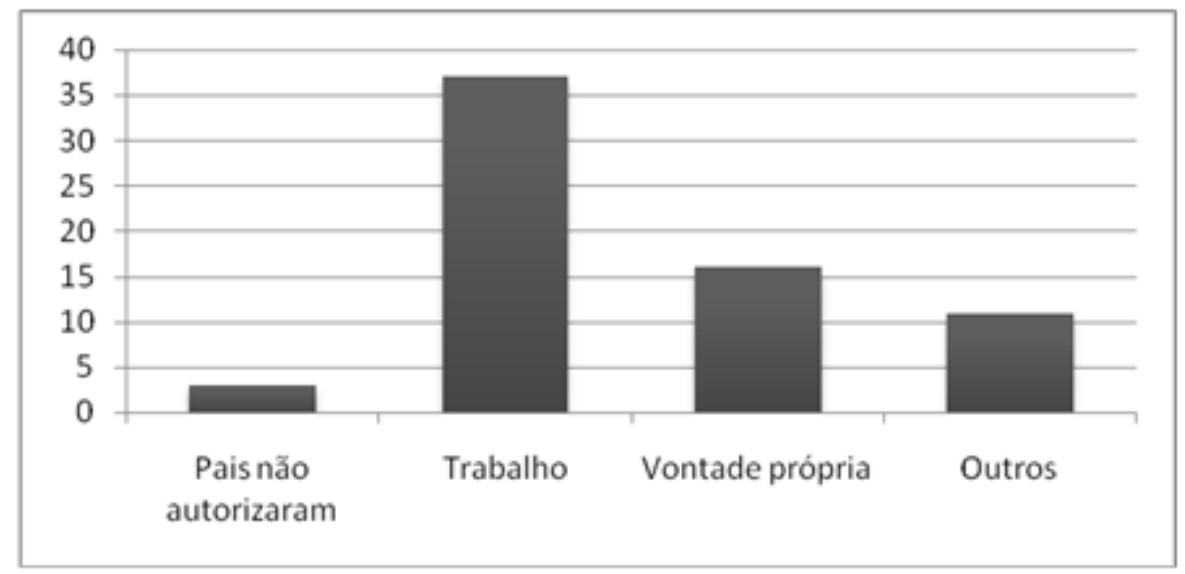

Figura 7: Motivo pelo qual os participantes deixaram de frequentar a escola regular em idade própria.

$\mathrm{Na}$ Figura 7, pode-se perceber que a maioria dos estudantes parou de estudar porque precisou adentrar ao mercado de trabalho. Uma das causas para que isso acontecesse era a necessidade de contribuir com a renda familiar desde muito cedo, pois na época em que tinham 7 ou 8 anos de idade era permitido o trabalho infantil; dessa forma, era comum que muitas pessoas deixassem seus estudos para trabalharem e auxiliar suas famílias.

A Figura 8 apresenta os motivos pelos quais os participantes voltaram a estudar. Nessa questão, considerou-se o fato do participante ter voltado a estudar por exigência do trabalho, o participante ter retornado aos bancos escolares por vontade própria, e, por último, o motivo outros (Ex: casamento, gravidez precoce, detenção).

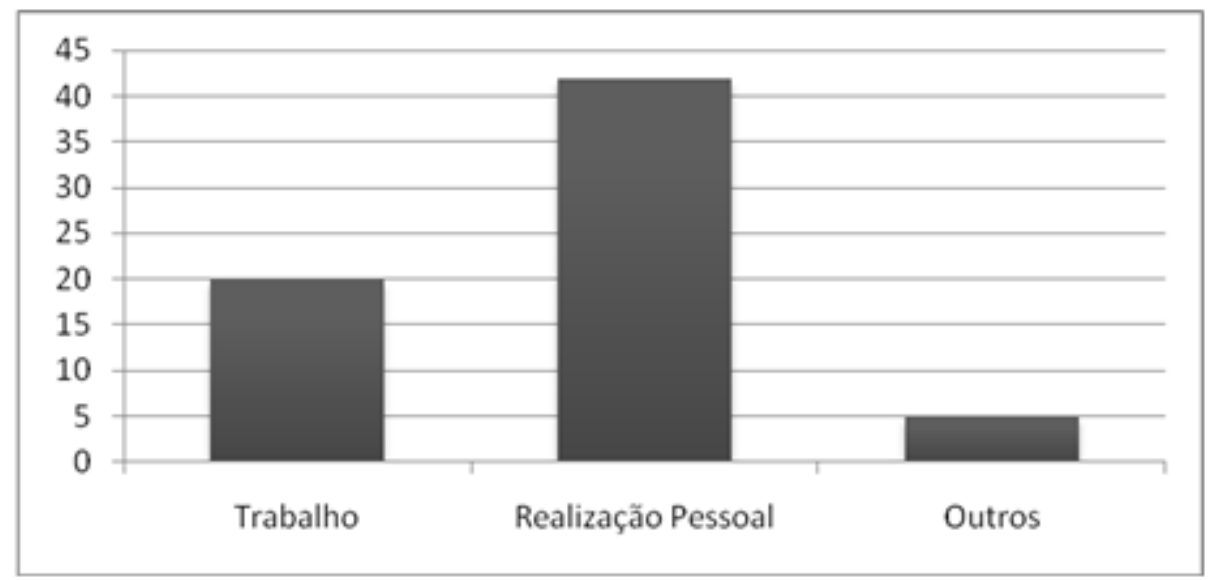

Figura 8: Motivo pelo qual os estudantes jovens e adultos retornaram à escola. 
Com os dados apresentados na Figura 8, pode-se perceber que a maioria dos estudantes atribuiu seu retorno aos estudos à sua própria realização pessoal (42\%), ou seja, voltaram a estudar por vontade própria e por perceberem a necessidade dos estudos em meio à sociedade letrada.

\subsection{Dados descritivos da amostra em relação ao desempenho escolar em função da faixa etária $e$ Diferenças entre os grupos em relação ao desempenho escolar}

A seguir, serão apresentados os dados referentes ao desempenho escolar de cada grupo. A Tabela 4 apresenta os dados referentes ao Grupo 1 de participantes, quanto ao desempenho escolar nos subtestes de escrita, aritmética, leitura e no TDE de forma geral.

Tabela 4: Médias dos escores dos subtestes de escrita, aritmética, leitura e geral do TDE do Grupo 1.

\begin{tabular}{lcccc}
\hline & TDE Esc. & TDE Arit. & TDE Leit. & TDE Geral \\
\hline Mínimo & 2 & 3 & 5 & 19 \\
Máximo & 32 & 21 & 70 & 120 \\
Média & 15,64 & 12,21 & 49,14 & 77 \\
\hline
\end{tabular}

Conforme os dados apresentados na Tabela 4 e considerando o valor máximo que o participante poderia ter obtido em cada subteste do TDE, pode-se observar que a média do subteste de escrita ficou abaixo da metade da pontuação permitida pelo teste $(17,5)$, o mesmo se verifica em relação ao subteste de aritmética(19). Já com o subteste de leitura, os participantes obtiveram pontuação acima de $50 \%$ de acertos no teste, assim como em relação à pontuação geral do TDE. Isso significa dizer que, de maneira geral, a maior dificuldade apresentada pelos participantes da pesquisa foi em relação à escrita e à aritmética. A leitura, conforme mostram os resultados, foi mais fácil para esses participantes.

Os resultados do Grupo 2, referentes ao desempenho escolar, são apresentados na Tabela 5. 
Tabela 5: Médias dos escores dos subtestes de escrita, aritmética, leitura e geral no TDE do Grupo 2.

\begin{tabular}{lllll}
\hline & TDE Esc. & TDE Arit. & TDE Leit. & TDE Geral \\
\hline Mínimo & 1 & 3 & 5 & 15 \\
Máximo & 33 & 21 & 70 & 123 \\
Média & 15,32 & 12,39 & 48,25 & 75,96 \\
\hline
\end{tabular}

Como se pode observar, o Grupo 2 obteve média de pontos no subteste de escrita abaixo da metade da pontuação permitida pelo teste, o que ocorreu também quanto à média de pontos no subteste de aritmética. Porém, tanto no subteste de leitura, quanto na pontuação geral do TDE, as médias ficaram acima de $50 \%$ da pontuação máxima do teste. Os participantes do grupo 2 obtiveram médias semelhantes às obtidas pelo grupo 1, pois tiveram mais dificuldade nos subtestes de escrita e aritmética e mais acertos no subteste de leitura.

$\mathrm{Na}$ tabela a seguir, são apresentados os resultados referentes ao desempenho escolar do Grupo 3.

Tabela 6: Médias dos escores dos subtestes de escrita, aritmética, leitura e geral do TDE do Grupo 3.

\begin{tabular}{lcccc}
\hline & TDE Esc. & TDE Arit. & TDE Leit. & TDE Geral \\
\hline Mínimo & 4 & 4 & 5 & 20 \\
Máximo & 35 & 27 & 70 & 132 \\
Média & 19,60 & 14,20 & 57,24 & 91,04 \\
\hline
\end{tabular}

O Grupo 3 teve uma pontuação acima de 50\% nos subtestes de escrita e leitura e no desempenho geral do TDE. Apenas no subteste de aritmética esse grupo apresentou pontuação abaixo da metade da pontuação máxima permitida pelo teste. $\mathrm{O}$ grupo 3 se diferenciou dos grupos 1 e 2 quanto aos resultados obtidos no subteste de escrita. Com isso, os participantes mais velhos parecem não ter tido dificuldade em escrever, ao contrário dos participantes dos grupos 1 e 2. Por outro lado, o grupo 3 apresentou resultados semelhantes ao dos grupos 1 e 2 com relação aos subtestes de aritmética, leitura e TDE geral, apresentando dificuldade com relação à aritmética e mais facilidade com relação à leitura. 
A fim de verificar se os grupos se diferenciavam em relação ao desempenho no TDE, foi aplicado o teste Kruskall-Wallis. O resultado dessa análise revelou que não houve diferenças entre os grupos pois, no subteste de escrita $(\mathrm{p}=0,254)$, aritmética $(\mathrm{p}=0,380)$, leitura $(0,155)$ e TDE geral $(\mathrm{p}=0,149)$, os valores de $p$ foram maiores que 0,05 . Com isso, pode-se dizer que não houve diferenças com relação ao desempenho em escrita, leitura e aritmética desses estudantes, embora pertencessem a faixas etárias bem diferentes.

\section{Discussão}

Este estudo foi conduzido com o objetivo de caracterizar o perfil de um grupo de estudantes da Educação de Jovens e Adultos e avaliar o desempenho escolar desses estudantes. Resgatando um dos objetivos deste trabalho, que consistiu em caracterizar o perfil de um grupo de estudantes da Educação de Jovens e Adultos - EJA, pode-se dizer que encontrou-se um grupo bastante heterogêneo no que diz respeito à faixa etária, aos anos de escolarização cursada e ao tempo transcorrido para retorno aos estudos, dentre outras características. Com relação à idade dos participantes, chamou a atenção o fato deste grupo ser composto por estudantes relativamente jovens, pois $21 \%$ eram estudantes com idade entre 14 e 24 anos, $42 \%$ com idades entre 27 e 38 anos e $37 \%$ de estudantes de 40 a 61 anos de idade. Outro dado interessante foi relativo ao sexo e ao estado civil dos participantes, pois a população era composta por mais homens solteiros e jovens $(64,3 \%$ - grupo 1$)$ e mulheres casadas $(32,1 \%$ - grupo 2$)$.

O estudo também investigou os motivos que levaram os indivíduos ao abandono do sistema regular de ensino, bem como o quê os fizeram com que retornassem aos bancos escolares. $\mathrm{Na}$ amostra como um todo, os dados do presente estudo revelaram que a maioria dos participantes deixou os estudos por motivo de trabalho, outros por vontade própria, seguidos por aqueles que não especificaram os motivos e uma porcentagem bem menor deles relataram que os pais não autorizaram a continuidade dos estudos, na época regular de escolarização. Dentre os motivos não especificados, denominados como “outros", uma parte dos participantes revelou motivos relacionados à criminalidade (detenção), casamento e filhos.

Quando se trata dos resultados específicos de cada grupo, separados por faixa etária, constatou-se que o grupo de participantes mais jovens (grupo 1) relatou com maior frequência ter interrompido os estudos por vontade própria. Por sua vez, o grupo de participantes mais "maduros" (grupo 2) e o grupo de participantes mais velhos (grupo 3) mencionaram ter abandonado os estudos por motivo de trabalho. Tais resultados reafirmam os achados de outros estudos da área (ANJOS; GOMES; SOUZA, 2012; CALIATTO; MARTINELLI, 2013; NAIFF; NAIFF, 2008; SIQUEIRA, 2009). Com relação ao motivo de retorno à escola, a maior frequência de resposta dos três grupos foi ter voltado a estudar por realização pessoal, entendida neste estudo como uma forma de se sentirem produtivos, de perspectiva de melhoria de vida e de serem indivíduos ativos na sociedade. 
Importante destacar que a justificativa de abandono dos estudos por necessidade de entrar no mercado de trabalho e contribuir com a renda familiar, argumento este mais utilizado pelos participantes que tinham idades entre 40 a 61 anos, também foi o argumento dos adultos investigados no estudo realizado por Siqueira (2009). O autor argumenta em relação a este dado que era comum as crianças, principalmente da zona rural, interromperem seus estudos para aprenderem um ofício e contribuir com a renda familiar, pois havia um interesse da família e da própria criança para que isso acontecesse, já que nem sempre se tinha motivação para continuar os estudos, devido às dificuldades encontradas com relação à aprendizagem dos conteúdos escolares.

Essa situação também era reforçada uma vez que não havia lei específica que garantisse o acesso e permanência da criança na escola, bem como a proibição de trabalho infantil, como esclarece o artigo 403 Lei $n^{\circ} 10.097$ de 2000, conhecida como lei da aprendizagem. Por outro lado, os motivos de retorno aos estudos de $63 \%$ dos participantes desse estudo foi a realização pessoal, motivo este também apontado com maior frequência pelos estudantes da EJA no estudo realizado por Anjos; Gomes e Souza (2012), que constataram que o retorno teve fundamento na busca de conhecimentos e na necessidade de aperfeiçoamento para o mercado de trabalho.

Ao analisar as características dos estudantes encontradas nesse estudo, qual seja, na sua maioria jovens, solteiros, do sexo masculino e mulheres casadas, é possível hipotetizar que tais características podem estar ancoradas em três questões principais. A primeira é o fato de o estudante jovem deixar o ensino regular por motivo de trabalho e abandonar os estudos por não conseguir conciliar os dois compromissos e, ao sentir a necessidade de retornar à escola, às vezes por exigência do próprio trabalho, migra para as turmas de EJA por ser no período noturno e também por ser uma opção mais aligeirada para o término dos estudos.

A segunda questão, que se pode inferir sobre a grande presença de jovens na EJA, principalmente com relação aos indivíduos do sexo masculino, é a vulnerabilidade às adversidades que estes enfrentam ao longo da vida, pois muitos estudantes se encontram em condições de pobreza extrema, uso de drogas, exploração juvenil, violência e até mesmo de liberdade assistida. A educação para esses indivíduos não é vista como prioridade, fazendo com que esses jovens abandonem a escola com mais frequência e, quando decidem voltar, anos depois, a EJA é a modalidade de ensino em que são mais bem acolhidos. Por último, a terceira questão atinge as jovens do sexo feminino. Em muitos casos, sabe-se que as mulheres abandonam os estudos por motivo de gravidez, ainda na adolescência, e casamento e, ao decidirem retornar aos estudos, buscam a EJA, como relatado por muitas das estudantes, o que justificaria a considerável porcentagem $(32,1 \%)$ de mulheres em idade mais madura (grupo $2-27$ a 38 anos de idade).

No que diz respeito ao segundo objetivo desse estudo, que buscou investigar os conhecimentos escolares relativos à escrita, leitura e aritmética desses estudantes, a avaliação desses conhecimentos revelou que os participantes dos grupos 1 e 2 tiveram baixo desempenho em escrita e aritmética, mas obtiveram melhores resultados em leitura. Já o 
grupo 3 obteve bom desempenho no subteste de escrita e leitura e não se saiu bem no subteste de aritmética. De modo geral, a maioria dos participantes (grupos 1 e 2) apresentou um baixo desempenho em escrita e aritmética, enquanto todos os participantes, independentemente da idade, tiveram facilidade com relação à leitura. Esses dados reforçam os achados de Camargo e Martinelli (2006) que mostram que, na percepção dos estudantes desta modalidade de ensino, a escrita e atividades de matemática foram apontadas como as principais dificuldades encontradas. Caliatto e Martinelli $(2005,2008)$ também investigaram a escrita de estudantes da EJA e encontraram muitas dificuldades relativas ao domínio das regras ortográficas na amostra investigada.

Com relação ao desempenho satisfatório que obtiveram em leitura, algumas inferências podem ser feitas. Os alunos pertencentes à EJA e que deixaram de frequentar o ensino na idade regular, embora tenham se afastado do ensino formal e, com isso, das habilidades exigidas pela escola, tiveram que desenvolver outras habilidades semelhantes para lidar com as demandas da vida em sociedade. Nesse sentido, jovens e adultos podem possuir dificuldades com relação ao ensino formal, mas são capazes de lidar com as demandas de vida diária, como identificar um ônibus, produtos no supermercado, remédios, receitas culinárias e todas as informações que estão inseridas no mundo letrado. Com isso, é compreensível que os participantes tenham obtido resultados baixos quando se trata de escrita e aritmética, as quais requerem habilidades mais técnicas, como regras ortográficas e resoluções aritméticas que deveriam ser sistematizadas no papel, e resultados mais satisfatórios quando se trata de leitura, a qual se assemelha mais às condições a que foram expostos ao longo da vida.

Os resultados referentes à comparação entre os grupos de participantes, quanto ao desempenho escolar, mostraram que não houveram diferenças significativas entre os grupos, o que significa que os participantes, independentemente de sua idade, revelaram desempenho escolar semelhante. Esse dado chama a atenção, uma vez que evidenciou que os estudantes mais jovens (pertencentes ao grupo 1 e com idades entre 14 e 24 anos) apresentaram desempenho escolar semelhante aos estudantes mais velhos, com idades entre 40 e 61 anos. Ao considerar que os estudantes mais jovens se afastaram da escola há menos tempo que os estudantes mais velhos, era de se esperar que os estudantes do grupo 1 apresentassem desempenho superior aos integrantes do grupo 2, mesmo levando em conta a experiência de vida que estudantes mais velhos possam ter acumulado ao longo dos anos. Esse dado parece ser bastante relevante e merece ser mais investigado, principalmente no que diz respeito à condução do processo de ensino-aprendizagem que vem sendo realizado pelas escolas.

\section{Considerações finais}

Os dados revelados por este estudo apontam para um sistema de educação que parece não suprir as demandas de escolarização para essa clientela, embora também devam ser vistos com parcimônia, tendo em vista que muitas dificuldades podem ser apontadas em estudos desta natureza. Foi possível perceber durante a coleta de dados que os participantes possuem 
muitas dificuldades na realização das atividades solicitadas e na compreensão do que deve ser realizado. Grande parte dessa dificuldade também pode ser atribuída à ausência de recursos adequados e que levem em conta as especificidades dessa população, principalmente com relação à avaliação das habilidades de escrita, leitura e aritmética.

Pontua-se que, as dificuldades escolares encontradas pelos estudantes da educação de jovens e adultos podem ser decorrentes de inúmeros fatores, dentre eles os que dizem respeito ao contexto escolar e à forma como se dá o processo de ensino-aprendizagem dessa população. Nesse sentido, considera-se que um dos principais pontos a serem pensados com relação ao processo de escolarização desses alunos é que este deve estar pautado no perfil e nas reais necessidades dessa população, de maneira a permitir que sejam criadas condições para que esses alunos realmente aprendam, que tenham não só recursos didáticos e tecnológicos adequados, boa estrutura física da escola, horário e tempo de aula pertinentes à realidade dos alunos, mas também aulas dinâmicas, contextualizadas e significativas, que façam sentido e os motive a permanecer e ter sucesso na escola.

Assim, é importante considerar que há uma necessidade de que dados empíricos, que retratem o real domínio de conhecimentos adquiridos pelos estudantes que cursam esta modalidade de ensino, possam estar disponíveis. Acredita-se que informações que permitam que se conheça acerca das reais capacidades ou dificuldades desses alunos, em seu processo de escolarização, possam auxiliar os professores na estruturação de programas mais adequados ao atendimento desses alunos. Nesse sentido, espera-se também que outras lacunas de investigação dessa modalidade de ensino possam ser exploradas, que promovam uma reflexão mais ampla e que abarquem não somente as políticas públicas, que foram e vêm sendo realizadas no âmbito da alfabetização de adultos, mas que permitam também uma reflexão sobre o processo de ensino e aprendizagem realizado em sala de aula.

\section{Referências}

ANJOS, L. A.; GOMES, G. P.; SOUZA, J.B. A prática pedagógica da EJA: refletindo sobre as singularidades e o perfil dos educandos. In: Anais da Semana de Pedagogia. Edição atual, v. 1, n. 1, Jequié, 2012.

BARCELOS, L. B. O que é qualidade na educação de jovens e adultos?. Educ. Real., Porto Alegre, v. 39, n. 2, p. 487-509, jun. 2014 .

BRASIL. Lei 9.394, de 20 de dezembro de 1996. Lei de Diretrizes e Bases da Educação

Brasileira(LDB). Brasília, 1996.

. Ministério da Educação e do Desporto. Relatório Educação para todos no Brasil 20002015, jun. 2014. Disponível em $<$ http://portal.mec.gov.br/index.php?option=com_docman\&view=download\&alias=15774-eptrelatorio-06062014\&Itemid=30192>. Acesso em 05/06/2016. 
Lei no 10.097 de 19 de dezembro de 2000. Senado Federal, CEGRAF, 2000.

CALIATTO, S. G.; MARTINELLI, S. C. Avaliação do reconhecimento de palavras em jovens e adultos. Psicologia: Revista da Vetor Editora, São Paulo, v.6, n.1, Jun., 2005.

CALIATTO, S. G.; MARTINELLI, S. C. Avaliação da escrita em jovens e adultos. Revista Brasileira de Estudos pedagógicos, Brasília, v. 89, n. 222, p. 273-294, maio/ago. 2008.

CALIATTO, S. G.; MARTINELLI, S. C. Aprendizagem escolar de estudantes da educação de jovens e adultos. Revista Educação em Questão, Natal, v. 47, n. 33, p. 86-108, set./dez., 2013.

CAMARGO, P. S. A. S.; MARTINELLI. Educação de adultos: percepções sobre o processo ensinoaprendizagem. Revista Semestral da Associação Brasileira de Psicologia Escolar e Educacional, v.10, n.2, jul/dez, 2006.

CATELLI JR., R.; GISI, B.; SERRAO, L. F. S. Encceja: cenário de disputas na EJA. Revista Brasileira de Estudos Pedagógicos, Brasília, v. 94, n. 238, dez., 2013.

GADOTTI, M. Educação de jovens e adultos: teoria, prática e proposta. São Paulo: Cortez, 2003.

HADDAD, S.; DI PIERRO, M. C. Aprendizagem de jovens e adultos: avaliação da década da educação para todos. São Paulo Perspectiva, São Paulo, v. 14, n. 1, mar., 2000.

HAAS, C.; GONCALVES, T. G. G. L. Em tempos de democratização do direito à educação: como têm se delineado as políticas de acesso à eja aos estudantes com deficiência no Rio Grande do Sul?. Rev. bras. educ. espec., Marília, v. 21, n. 4, p. 443-458, dez. 2015.

INSTITUTO BRASILEIRO DE GEOGRAFIA E ESTATÍSTICA (2012). Síntese de Indicadores Sociais. Disponível em <http://www.ibge.gov.br>. Acesso em 05/ 06/ 2016.

INSTITUTO PAULO MONTENEGRO. INAF BRASIL-2011/2012. Indicadorde alfabetismo

funcional: principais resultados. Disponível

em:<http://www.ipm.org.br/download/informe_resultados_inaf2011_versao\%20final_12072012b.pdf $>$. Acesso em 01/11/2013.

NAIFF, L. A. M. E NAIFF, D. G. M. Educação de jovens e adultos em uma análise psicossocial: representações e práticas sociais. Psicologia \& Sociedade, v.20, n.3, p. 402-407, 2008.

PIERRO, M. C. Di; HADDAD, S. Transformações nas políticas de Educação de Jovens e Adultos no Brasil no início do terceiro milênio: uma análise das agendas nacional e internacional. Cad. CEDES, Campinas, v. 35, n. 96, p. 197-217, ago. 2015.

SIQUEIRA, A. B. O retorno de jovens e adultos aos estudos formais após 20, 30, 40 anos. Poiésis Revista do Programa de Pós-graduação em Educação da Universidade do Sul de Santa Catarina - UNISUL, Tubarão, v. 2, n. 1, p. 32 - 43, jan./jun. ,2009. 
STEIN, L. M. TDE: teste do desempenho escolar. Manual para aplicação e Interpretação. São Paulo: Casa do Psicólogo, 1994.

VOLPE, G. C. M. O financiamento da educação de jovens e adultos em municípios mineiros no período de 1996 a 2006: até quando migalhas?. Rev. Bras. Educ., Rio de Janeiro, v. 18, n. 54, p. 693716, set. 2013.

Recebido em: 04/10/2014

Revisado em: 22/06/2016

Aprovado para publicação em: 30/06/2016

Publicado em: 31/08/2016 